\title{
Selective Activation Induced Cleavage of the NR2B Subunit by Calpain
}

\author{
Kelly L. Simpkins, ${ }^{1}$ Rodney P. Guttmann, ${ }^{5}$ Yina Dong, ${ }^{1}$ Zhaoming Chen, ${ }^{3}$ Set Sokol, ${ }^{1}$ Robert W. Neumar, ${ }^{3}$ and \\ David R. Lynch ${ }^{1,2,4}$ \\ Departments of ${ }^{1}$ Neurology, ${ }^{2}$ Pediatrics, and ${ }^{3}$ Emergency Medicine, University of Pennsylvania, Philadelphia, Pennsylvania 19104-4306, and ${ }^{4}$ The \\ Children's Hospital of Philadelphia, Philadephia, Pennsylvania 19104-4318, and ${ }^{5}$ Sanders-Brown Center on Aging, University of Kentucky, Lexington, \\ Kentucky 40536
}

\begin{abstract}
Although activation of calcium-activated neutral protease (calpain) by the NMDA receptor has been suggested to play critical roles in synaptic modulation and neurologic disease, the nature of its substrates has not been completely defined. In this study, we examined the ability of calpain to cleave the NMDA receptor in cultured hippocampal neurons. Activation of the NMDA receptor by agonist application led to rapid calpain-specific proteolysis of spectrin and decreased levels of NR2A/2B subunits. Cleavage of the NR2A/2B subunit created a $115 \mathrm{kDa}$ product that retained the ability to bind ${ }^{125} \mathrm{I}-\mathrm{MK}-801$ and is predicted to be active. Increases in levels of this product appeared within $5 \mathrm{~min}$ of NMDA receptor activation and were stable for periods of $>30 \mathrm{~min}$. Subtype-specific antibodies demonstrated that the NR2B subunit was cleaved in these primary cultures, but the NR2A subunit was not. An inhibitor of calpain blocked both the decrease of intact NR2B and the increase of the low molecular weight form, whereas neither caspase nor cathepsin inhibitors had an effect on these events. Cell surface biotinylation experiments demonstrated that the $115 \mathrm{kDa}$ fragment remained on the cell surface. This NR2B fragment was also found in the rat hippocampus after transient forebrain ischemia, showing that this process also occurs in vivo. This suggests that calpain-mediated cleavage of the NR2B subunit occurs in neurons and gives rise to active NMDA receptor forms present on the cell surface after excitotoxic glutamatergic stimulation. Such forms could contribute to excitotoxicity and synaptic remodeling.
\end{abstract}

Key words: glutamate; calpain; protease; excitotoxicity; NMDA; stroke

\section{Introduction}

Glutamate, the major excitatory neurotransmitter in the CNS, acts at several postsynaptic receptors. One of these, the NMDA receptor, is a cation channel permeable to calcium and sodium. Calcium entering through the NMDA receptor activates many cellular enzymes such as calpain, protein kinases, and neuronal nitric oxide synthase (Lynch and Guttmann, 2002). NMDA receptors play a key role in excitotoxicity, in which their sustained activation leads to excess neuronal cell death (Lynch and Guttmann, 2002).

A series of cDNAs encoding the subunits of the NMDA receptor (designated NR1, NR2A-2D) have been cloned. In most situations, both an NR1 and an NR2 subunit are required for receptor function, with different combinations of subunits producing receptors with distinct properties (Dingledine et al., 1999; Lynch and Guttmann, 2002). Compared with NR1, NR2 subunits possess an extra $50 \mathrm{kDa}$ of protein in the intracellular $\mathrm{C}$ terminus. Receptors containing C-terminally truncated NR2 subunits are

Received Aug. 27, 2003; revised 0ct. 17, 2003; accepted 0ct. 18, 2003.

This work was supported by National Institutes of Health Grants NS39126 and NS45986 and a Beeson Scholar Award from American Federation for Aging Research to D.R.L. We thank Margaret Maronski for preparation of neuronal cultures.

Correspondence should be addressed to Dr. David R. Lynch, Division of Neuroscience Research, Children's Hospital of Philadelphia, 502 Abramson Building, Philadelphia, Pennsylvania 19104-4318. E-mail: lynch@pharm.med.upenn.edu.

Copyright $\odot 2003$ Society for Neuroscience $\quad 0270-6474 / 03 / 2311322-10 \$ 15.00 / 0$ relatively similar electrophysiologically to native receptors, but mice having receptors lacking only the C-terminal region of $\mathrm{NR} 2 \mathrm{~A}$ or NR2C have the same abnormal phenotype as animals lacking the entire subunit. This suggests that many NMDA receptor functions require intracellular events mediated by the region within the C terminus (Sprengel et al., 1998).

The C-terminal region of the NR2 subunit binds intracellular anchoring proteins, is necessary for regulation by second messengers, and is a potential substrate for the calcium-activated neutral protease calpain (Kim et al., 1996; Bi et al., 1998a,b; Grant et al., 1998; Zheng et al., 1999; Guttmann et al., 2001, 2002). Calpain regulates numerous proteins, including cytoskeletal components, integral membrane proteins, and receptors, and plays a critical role in long-term potentiation, synaptic plasticity, and excitotoxicity (Wang, 2000). Calpain I (hereafter called calpain) typically cleaves substrates in a limited manner, leading to the formation of large products that remain active (Hell et al., 1996; Johnson and Guttmann, 1997).

The proposed roles of calpain in the brain are directly connected to NMDA receptor activation (Vanderklish et al., 1996). Neuronal calpain is physiologically activated primarily by the NMDA receptor, reflecting its high calcium permeability and relative lack of desensitization (Adamec et al., 1998); however, the physiological substrates of calpain are not well understood. The NR2A subunit is cleaved by calpain in vitro and in heterologous systems at two specific sites in the C-terminal region, sug- 
gesting that calpain directly modulates NMDA receptor activity, function, or localization (Bi et al., 1998a,b; Guttmann et al., 2001). Studies examining the cleavage of NMDA receptors in neurons have been equivocal, with relatively long agonist exposures being needed to demonstrate cleavage of NR2 subunits (Bi et al., 1998a,b). Although calpain cleavage in vitro is limited to the C-terminal region, neuronal studies have not clearly identified truncated forms of the receptor, and the NR2 subtype specificity is unknown (Bi et al., 1998a,b; Dingledine et al., 1999). To address these questions, we have characterized rapid cleavage of the NR2B subunit in hippocampal neurons after glutamatergic stimulation, identified the region of the protein that is cleaved, and determined that these subunits remain on the cell surface after cleavage. These results address mechanisms of NMDA receptor turnover and may have implications for excitotoxicity.

\section{Materials and Methods}

Materials. Glutamate, glycine, ketamine, aprotinin, pepstatin, phenylmethylsulfonyl fluoride (PMSF), and anti-actin were from Sigma (St. Louis, MO); minimal essential medium, penicillin-streptomycin, and glutamine were from Invitrogen (Carlsbad, CA). Fetal bovine serum was from Hyclone Laboratories (Logan, UT). Dizocilpine (MK-801) was from Sigma/RBI (Natick, MA). ${ }^{125}$ I-MK-801 was from Perkin-Elmer Life Sciences (Boston, MA). Human embryonic kidney (HEK) 293 cells were from American Type Culture Collection (Manassas, VA). Immobilized monomeric avidin and sulfo- $\mathrm{N}$-hydroxysulfosuccinimide (NHS)biotin were from Pierce (Rockford, IL). Antibodies from Chemicon International (Temecula, CA) included AB 1516 (NR1, C-terminal, amino acids 909-938) and AB 1557 (NR2B specific, C-terminal, amino acids 984-1104). An N-terminal antibody to amino acids 25-130 of NR2C (A-6475) was from Molecular Probes (Eugene, OR) (Guttmann et al., 2001). This antibody recognizes NR2A and NR2B (both $170 \mathrm{kDa}$ ) as well as NR2C (135 kDa) (Guttmann et al., 2001). An NR2A-specific antibody (AB 6313) to the C-terminal 200 amino acids was from Upstate Biotechnology (Lake Placid, NY). AB38, which recognizes calpain-cleaved spectrin, was produced as described previously (Roberts-Lewis et al., 1994). Calpain inhibitor III (CalI3) (MDL 28170; Z-Val-Phe-CHO), caspase inhibitor II (CaspI2) (Ac-Val-Ala-Asp-CHO), cathepsin inhibitor I (Cath I1)(Z-Phe-Gly-NHO-Bz), and porcine calpain I were purchased from Calbiochem (San Diego, CA). Rabbit calpastatin cDNA was a generous gift from Dr. Masatoshi Maki (Nagoya University, Nagoya, Japan). The cDNA for NR2B was from mouse (Lynch et al., 1994; Gallagher et al., 1997).

Preparation of primary neuronal cultures. Embryonic rat hippocampal neurons were prepared by previously described techniques (Wilcox et al., 1994) and include a heterogeneous mixture of pyramidal and nonpyramidal neurons of multiple morphologies. Hippocampal tissue was harvested from Sprague Dawley rat pups (Charles River) on embryonic day 17 , gently minced and trypsinized $\left[0.027 \% ; 37^{\circ} \mathrm{C} ; 7 \% \mathrm{CO}_{2}\right.$ for $\left.20 \mathrm{~min}\right]$, and then washed with $1 \times$ HBSS. The tissue was triturated in warm media (10\% defined, heat-inactivated fetal bovine serum), 10\% Hams F12 medium, and 80\% DMEM with penicillin-streptomycin), and cells were plated at a density of $6 \times 10^{5}$ viable cells per $35 \mathrm{~mm}$ culture dish onto poly-L-lysine-coated coverslips. Neurons were maintained at $37^{\circ} \mathrm{C}, 5 \%$ $\mathrm{CO}_{2}$ and fed with neurobasal media with B27 by addition of $50 \mu \mathrm{l}$ of media into a $2 \mathrm{ml}$ well. Non-neuronal cell growth was inhibited with cytosine arabinoside at 7-10 d in vitro. Cells were used after 2-4 weeks in culture.

Incubation in agonists and drug treatments. For studies of calpain cleavage, cells were rinsed twice with $1 \times$ PBS and then preincubated for 30 min in HBSS with inhibitors or vehicle. The solution was removed and replaced with an identical solution containing glutamate, glycine (100 $\mu \mathrm{M}$ each for routine experiments), and any inhibitors or vehicles. Drugs were dissolved in stock solutions at $1000 \times$ or greater in appropriate vehicles. For studies using MK-801 or ifenprodil, drugs were dissolved in water and used at final concentrations of 100 and $10 \mu \mathrm{M}$, respectively. Calpain inhibitor III, caspase inhibitor II, and cathepsin inhibitor I were dissolved in DMSO and used at 10, 3, and $10 \mu \mathrm{M}$, respectively. Final DMSO concentration was $\leq 0.1 \%$. For glutamate dose-response curves, the concentration of glutamate was varied from 1 to $100 \mu \mathrm{M}$, with the glycine concentration remaining $100 \mu \mathrm{M}$. In selected experiments, cell death was monitored using exclusion of trypan blue (Anegawa et al., 1995). After incubation in agonist, the solution was removed, and cells were immediately scraped into $1 \times$ Laemmli stop buffer without bromophenol blue, EGTA, or dithiothreitol (DTT) (Guttmann et al., 2001). Samples were boiled for $5 \mathrm{~min}$, and protein concentrations were determined using the bicinchoninic assay (Pierce). Bromophenol blue and DTT were then added, and the samples were then stored at $-20^{\circ} \mathrm{C}$ until used.

NR2B degradation in vitro by purified calpain I. Twenty-four hours after transfection of HEK293 cells, cells were rinsed with PBS and then scraped into $40 \mathrm{~mm}$ HEPES, $\mathrm{pH}$ 7.2, containing 2 mм EDTA, $2 \mathrm{~mm}$ EGTA, $1 \mathrm{~mm}$ phenylmethylsulfonyl fluoride, $10 \mu \mathrm{g} / \mathrm{ml}$ aprotinin, and 10 $\mu \mathrm{g} / \mathrm{ml}$ pepstatin. Samples were briefly sonicated on ice and stored in aliquots at $-80^{\circ} \mathrm{C}$ until use. For in vitro proteolysis, the homogenates were incubated in the presence of calpain I $(2.5 \mathrm{U} / \mathrm{ml})$ for $30 \mathrm{~min}$ in a buffer containing $1 \mathrm{mM} \mathrm{CaCl}_{2}, 5 \mathrm{~mm}$ dithiothreitol, and $40 \mathrm{~mm}$ HEPES, $\mathrm{pH}$ 7.2.

Calpain activity assay with Suc-LLVY-AMC. Twenty-four hours after transfection, cells were rinsed with serum-free medium, and the medium was replaced with serum-free media containing $100 \mu \mathrm{M}$ glutamate and $100 \mu \mathrm{M}$ glycine in the presence or absence of $100 \mu \mathrm{M}$ MK-801 in addition to $80 \mu \mathrm{M}$ Suc-LLVY-AMC. Cells were then placed in a $5 \% \mathrm{CO}_{2}$ incubator at $37^{\circ} \mathrm{C}$. After a $40 \mathrm{~min}$ incubation, the plates were read in a Victor ${ }^{2}$ fluorescence plate reader (Perkin-Elmer Wallac, Turku, Finland) at wavelength settings of 390 and $460 \mathrm{~nm}$ for excitation and emission, respectively. This assay is linear with cell number, and the activity measured is representative of calpain activity observed with protein substrates (Guttmann et al., 1997, 2002; Johnson and Guttmann, 1997).

${ }^{125} \mathrm{I}-\mathrm{MK}-801$ binding. Cell membranes were prepared as described previously (Lynch et al., 1994). Briefly, the membrane fractions were homogenized in assay buffer (20 mM HEPES, pH 7.5, $100 \mu \mathrm{m}$ glutamate, 100 $\mu \mathrm{M}$ glycine, and $300 \mu \mathrm{M} \mathrm{MgCl}_{2}$ ) and incubated at $37^{\circ} \mathrm{C}$ for $30 \mathrm{~min}$. Homogenates were then centrifuged, and the pellet was resuspended in assay buffer. This process was repeated two more times. Membrane suspensions were then assayed in saturating glycine $(100 \mu \mathrm{M})$, glutamate $(100 \mu \mathrm{M})$, spermidine $(100 \mu \mathrm{M}), \mathrm{MgCl}_{2}(100 \mu \mathrm{M})$, and $300 \mathrm{pM}{ }^{125} \mathrm{I}-\mathrm{MK}-$ 801 (Lynch et al., 1994). Membranes were harvested onto polyethyleneimine-coated glass fiber filters (Schleicher \& Schuell, Keene, NH), and the radioactivity was quantified using a Beckman (model 5500B) gamma counter.

Truncated forms of NR2. Truncated forms of NR2A and NR2B were made by standard molecular biological approaches. NR2B (del 11701482 ) was produced by cleaving the cDNA of full-length $\epsilon 2$ in $p R K 7$ with ApaI, isolating the major piece, and ligating it to itself. This yields a form of $\epsilon 2$ containing the first 1170 amino acids of wild-type followed by missense mutations for 20 amino acids before a premature stop codon. NR2B (del 1034-1370) was created by cleavage of $\epsilon 2$ in pRK7 with Esp I (Cel II) and ligation of the major piece back to itself. Truncated forms of NR2A (at amino acids 1279, 1051, and 895) were produced as described previously (Grant et al., 1998; Guttmann et al., 2001). Truncated forms were confirmed by restriction mapping and DNA sequencing.

Transfection of HEK293 cells. HEK293 cells were grown on tissue culture grade dishes (Corning; Corning Glassworks, Corning, NY) in MEM media containing $5 \%$ horse serum and $5 \%$ fetal bovine serum supplemented with $2 \mathrm{~mm}$ glutamine and $100 \mathrm{U} / \mathrm{ml}$ penicillin-streptomycin incubated in $5 \% \mathrm{CO}_{2}$ at $37^{\circ} \mathrm{C}$. Transfection of HEK293 cells was accomplished by calcium phosphate precipitation as described previously (Grant et al., 1997). Treatments were added $24 \mathrm{hr}$ after transfection. Ketamine $(300 \mu \mathrm{M})$ was added to the media during transfection to prevent NMDA receptor activation as described previously (Grant et al., 1998).

Western blotting. Thirty micrograms of total protein was loaded on a $7 \%$ polyacrylamide gel ( $10 \%$ for experiments examining actin). After SDS gel electrophoresis, proteins were transferred to nitrocellulose, blocked with $3 \%$ fetal bovine serum, and incubated with primary anti- 
body. Blots were then incubated with appropriate HRP-conjugated secondary antibodies and developed with enhanced chemiluminescence (Pierce).

Biotinylation. After treatment, cultures were placed on ice and rinsed twice with a cold rinsing solution containing PBS, pH 7.5, $1 \mathrm{~mm} \mathrm{MgCl}_{2}$, and $0.1 \mathrm{mM} \mathrm{CaCl}_{2}$ (Sims et al., 2000). Cells were then gently agitated at $4^{\circ} \mathrm{C}$ for $20 \mathrm{~min}$ in rinsing solution containing $1 \mathrm{mg} / \mathrm{ml} \mathrm{NHS}$-biotin. Cells were rinsed twice in quenching solution (rinsing solution with $100 \mathrm{mM}$ glycine added) and agitated at $4^{\circ} \mathrm{C}$ in quenching solution with $10 \mu \mathrm{M}$ MK-801 for $20 \mathrm{~min}$. Cells were washed and agitated for $1 \mathrm{hr}$ at $4^{\circ} \mathrm{C}$ in RIPA buffer [ $150 \mathrm{~mm} \mathrm{NaCl}, 1 \mathrm{~mm}$ EDTA, and $100 \mathrm{~mm}$ Tris $\mathrm{HCl}, \mathrm{pH}$ 7.4; $1 \%(\mathrm{v} / \mathrm{v})$ Triton X-100, 1\% (w/v) deoxycholate, 0.1\% (w/v) SDS] containing protease inhibitors $(1 \mu \mathrm{g} / \mathrm{ml}$ leupeptin, $250 \mu \mathrm{M}$ PMSF, $1 \mu \mathrm{g} / \mathrm{ml}$ aprotinin, $1 \mathrm{mg} / \mathrm{ml}$ trypsin inhibitor, and $1 \mathrm{~mm}$ iodoacetamide). Samples were harvested and centrifuged at $12,400 \mathrm{rpm}$ for $20 \mathrm{~min}$ at $4^{\circ} \mathrm{C}$. Separate aliquots of the lysate were taken for total lysate fraction, protein quantification, and incubation in avidin beads overnight at $4^{\circ} \mathrm{C}$. After overnight incubation, samples were centrifuged at $12,400 \mathrm{rpm}$ for $15 \mathrm{~min}$ in a microfuge, and the supernatant (the intracellular fraction) was removed. Sample solubilizing buffer ( $4 \times$; $8 \%$ SDS, $240 \mathrm{~mm}$ Tris, pH 6.8, 0.04\% bromophenol blue, $40 \%$ glycerol, $4 \%$ 2-mercaptoethanol) was added to both the total lysate and intracellular fractions. Avidin beads were then washed four times with RIPA buffer and incubated in $2 \times$ sample solubilizing buffer for $30 \mathrm{~min}$ at room temperature. Samples were then centrifuged for $5 \mathrm{~min}$ at $12,000 \mathrm{rpm}$, and the supernatant (the extracellular fraction) was removed and stored at $-20^{\circ} \mathrm{C}$. Thirty micrograms of each fraction was subjected to SDS-PAGE and Western blot analysis.

Image quantitation. Autoradiograms generated from Western blots were scanned using an Epson scanner in conjunction with Adobe Photoshop (Guttmann et al., 2001). Data was quantitated using imaging densitometry and analyzed using the NIH Image program. For quantitation of calpain-generated receptor products, values were normalized to maximal cleavage level for statistical analysis. For degradation of NMDA subunits, samples were normalized to the 30 min $100 \mu \mathrm{M}$ MK-801 control condition on a given blot.

Statistical analysis. Statistical differences were determined by ANOVA or $t$ tests using Instat software and considered significant at $p<0.05$. For comparisons in groups of more than two samples, ANOVA was initially used, followed by serial $t$ tests if the ANOVA value was significant.

Transient forebrain ischemia. All animal procedures were performed in accordance with NIH Guidelines for the Care and Use of Laboratory Animals and were approved by our Institutional Animal Care and Use Committee. Male Long-Evans rats (400-500 gm) were subjected to $10 \mathrm{~min}$ of transient forebrain ischemia using an established model initially described by Smith et al. (1984), modified by Gionet et al., (1992), and used routinely in our laboratory (Neumar et al., 2001; Zhang et al., 2002).

Briefly, rats were anesthetized with $1-1.5 \%$ halothane, orotracheally intubated, and mechanically ventilated with $30 \% \mathrm{O}_{2}$ and $70 \% \mathrm{~N}_{2} \mathrm{O} . \mathrm{P}_{\mathrm{CO}_{2}}$ values were kept between 35 and $45 \mathrm{mmHg}$, and temperature was maintained at $37.0-37.5^{\circ} \mathrm{C}$ throughout the procedure. Femoral arterial and venous catheters were placed by cut-down, and carotid arteries were exposed using aseptic technique. Transient forebrain ischemia was initiated by the combination of bilateral carotid occlusion and hypovolemic hypotension to a mean arterial blood pressure (MABP) of $30 \mathrm{mmHg}$. Hypovolemic hypotension was achieved by rapidly withdrawing blood from the femoral arterial catheter into a heparinized syringe and maintained during the ischemic period by withdrawal or infusion of blood through the femoral venous catheter. Once an MABP of $30 \mathrm{mmHg}$ is achieved, both carotid arteries were reversibly occluded with surgical aneurysm clips. The duration of ischemia was timed from when the aneurysm clips were placed. After $10 \mathrm{~min}$ of ischemia the aneurysm clips were removed and shed blood was reinfused. Rats were maintained on mechanical ventilation for $1 \mathrm{hr}$, after which vascular catheters were removed, surgical wounds were closed, and animals were extubated. Sham (uninjured) animals were subjected to anesthesia and surgical preparation without bilateral carotid occlusion and hypovolemic hypotension.

Rats were killed $48 \mathrm{hr}$ after injury, and brains were rapidly microdissected on an ice-chilled plate. The dorsal hippocampus was homogenized in 10:1 v/w homogenization buffer containing 10 mM HEPES, $\mathrm{pH} 7.4$,
$320 \mathrm{~mm}$ sucrose, $2.0 \mathrm{~mm}$ EGTA, $0.5 \mathrm{~mm} \mathrm{MgSO}_{4}, 2.0 \mathrm{~mm}$ 2-mercaptoethanol, $2.0 \mu \mathrm{g} / \mathrm{ml}$ aprotinin, $5 \mu \mathrm{g} / \mathrm{ml}$ leupeptin, $2 \mu \mathrm{g} / \mathrm{ml}$ pepstatin, and $0.1 \mathrm{~mm}$ PMSF $0.1 \mu \mathrm{g} / \mathrm{ml}$ Z-VAD-FMK. To generate synaptosomal fractions, hippocampal homogenates were centrifuged at $900 \times g$ for $10 \mathrm{~min}$ two times, and the pooled supernatant was centrifuged at 17,000 $\times g$ for 45 min two times. The 17,000 $\times g$ pellet was then resuspended in homogenization buffer, layered over a $20 / 40 \%$ discontinuous sucrose gradient, and centrifuged at $63,700 \times g$ for $45 \mathrm{~min}$. The band at the interface was then centrifuged at $20,000 \times g$ for $30 \mathrm{~min}$, and the pellet was resuspended in homogenization buffer. Protein concentration was determined by the Bradford method. Samples with diluted 1:1 in $2 \times$ Laemmli buffer and boiled for $5 \mathrm{~min}$ and then snap-frozen in dry ice-ethanol slurry until time of analysis.

\section{Results}

\section{Activation of calpain in hippocampal cultures}

To establish NMDA receptor-mediated calpain activation in hippocampal neurons, we incubated neuronal cultures in glutamate and glycine, followed by harvesting and Western blotting with an antibody (AB38) directed at the calpain-generated spectrin degradation product (Roberts-Lewis et al., 1994). The spectrin degradation fragment was produced rapidly, within $5 \mathrm{~min}$ of agonist application, and levels were markedly elevated after $30 \mathrm{~min}$ of agonist treatment. This increase was inhibited by the inclusion of the NMDA receptor antagonist MK-801 $(100 \mu \mathrm{M})(p<0.0001$ for $0 \mathrm{~min}$ compared with $30 \mathrm{~min}$; and for MK-801 with $30 \mathrm{~min}$; $n=13$ ) (Fig. $1 A, B$ ). Call3 also prevented the increase of the degradation product, whereas CasI2 and CathI1 did not (Fig. 1C). No inhibition was observed in agonist plus vehicle treatment (data not shown). This confirmed that NMDA receptor activation resulted in calpain activity in this preparation. Although both NR2A and NR2B subunits were present in this population (Fig. 1D), NMDA receptor-mediated calpain activity was not significantly inhibited by $10 \mu \mathrm{M}$ ifenprodil, an NR2B-selective antagonist (Fig. 1C) (Williams, 1993; Lynch et al., 1994, 1995). This suggested that receptors containing NR2B alone (commonly felt to be mostly extrasynaptic) are not necessary for activating calpain in this preparation (Stocca and Vicini, 1998; Tovar and Westbrook, 1999; Li et al., 2002).

\section{Cleavage of NR2 subunits in cultured hippocampal neurons}

We then investigated whether NR2 subunits might be rapidly cleaved under conditions that clearly activate calpain. Hippocampal neurons were incubated in glutamate and glycine and analyzed by Western blots using an $\mathrm{N}$-terminal antibody (A6475 ) that recognizes NR2A, NR2B, and NR2C subunits in transfected cells (Guttmann et al., 2001). In hippocampal neurons, this antibody recognized an incompletely resolved doublet species at $170 \mathrm{kDa}$ (designated NR2A/2B) that comigrated with NR2A and NR2B identified by subtype-selective antibodies (Fig. 1D). No $135 \mathrm{kDa}$ species characteristic of NR2C was observed, consistent with the lack of NR2C in forebrain (Nakanishi, 1992; Guttmann et al., 2001). We observed a decrease in full-length $\mathrm{NR} 2 \mathrm{~A} / 2 \mathrm{~B}$ immunoreactivity after $30 \mathrm{~min}$ agonist treatment $(p=$ 0.016 for 30 min vs 0 min; $n=13$ ) with the simultaneous increase in levels of a low molecular weight (LMW) species of $115 \mathrm{kDa}(0$ vs 30 min $=0.0044 ; n=12$ ) (Fig. $2 A$ ). Levels of this LMW species increased within 5 min of agonist application and were stable over time. The increased levels of the LMW fragment correlated temporally with the decrease of full-length NR2A/2B. In addition, there was a strong correlation between decreases of fulllength NR2A/2B and the increases in levels of the LMW fragment in individual experiments $\left(R_{\mathrm{s}}=-0.70 ; p=0.007 ; n=13\right)$, further showing that the decrease of full-length and the increase of 
A.

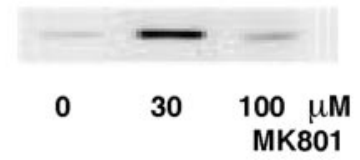

B.

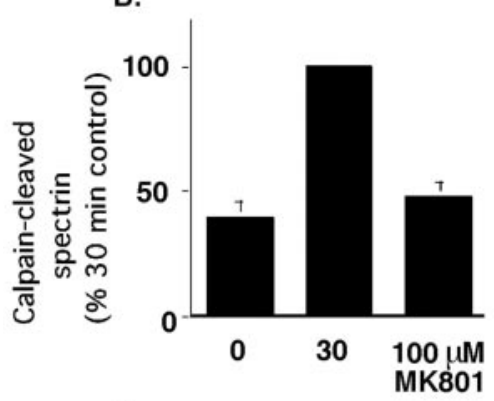

C.

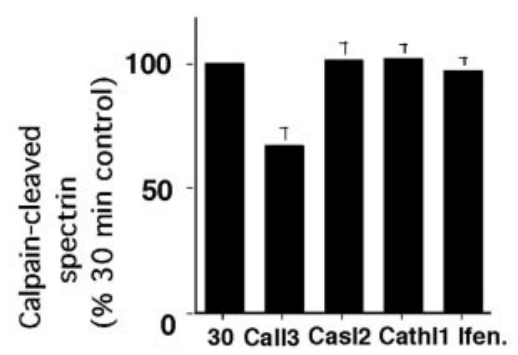

D.

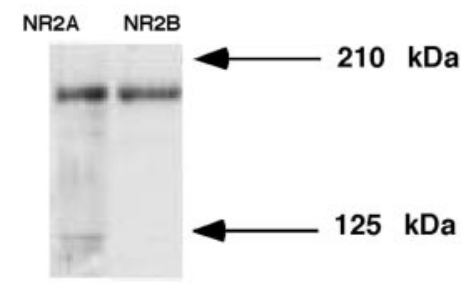

Figure 1. NMDA receptor-mediated calpain activation in hippocampal neurons. Thirty micrograms of total protein were separated by SDS-PAGE and probed for the calpain-produced spectrin degradation product (AB38). A representative Western blot and bar graph $(A, B)$ demonstrate elevated levels of this product after stimulation of NMDA receptors with $100 \mu \mathrm{m}$ glutamate and $100 \mu \mathrm{m}$ glycine for $30 \mathrm{~min}$, and inhibition of this effect by $100 \mu \mathrm{M}$ MK-801 ( $p<$ 0.0001 for $0 \mathrm{~min}$ compared with $30 \mathrm{~min}$; and for MK-801 with $30 \mathrm{~min} ; n=13$ ). The production of the spectrin degradation product was also inhibited by the presence of Call 3 in the treatment conditions, but not by Casl 2 or Cathl1 ( $p=0.0009$ by ANOVA; $p=0.0014$ for Call 3 vs 30 min; $p=$ n.s. for Casl2 and Cathl1; $n=10)(C$. When NR2B-containing receptors were selectively inhibited by ifenprodil (Ifen.), no change was found in production of the spectrin degradation product as shown in C. Blots probed with subunit-specific antibodies demonstrated the presence of both NR2A (AB 6313) and NR2B (AB 1557) in this population, as shown in D. These results suggest that receptors containing only $2 B$ are not required for activating calpain in hippocampal neurons. Error bars on bar graphs indicate SEM.

the LMW fragment were associated phenomena. Inclusion of 100 $\mu \mathrm{M}$ MK-801 in the treatment conditions prevented the decrease in full-length NR2A/2B (MK801 vs $30 \mathrm{~min}=0.0004 ; n=12)$ Fig. $2 B)$ and the increase in levels of the LMW fragment $(p=0.0135$ MK-801 vs 30 min; $n=12$ ) (Fig. $2 C$ ). Given the size of the LMW fragment and the location of the N-terminal epitope (amino acids 25-130), this fragment must be derived from C-terminal cleavage of NR2A or NR2B, or both, matching the results in heterologous systems (Guttmann et al., 2001, 2002). No significant cell death using Trypan blue exclusion was noted under the
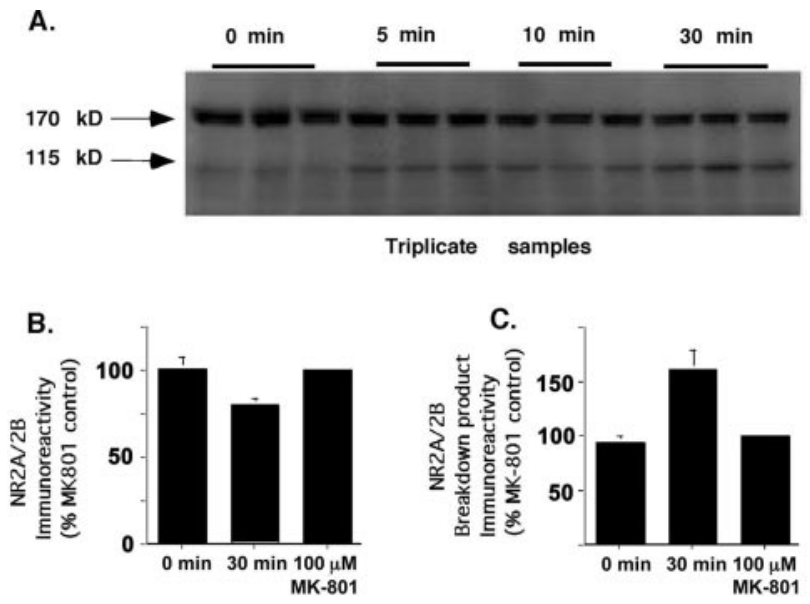

Figure 2. Effects of calpain activation on NR2 subunits in neurons. Neurons were exposed to NMDA receptor agonist stimulation over a $0-30$ min time course and subjected to Western blot analysis with an N-terminal antibody that recognizes NR2A, NR2B (both $170 \mathrm{kDa}$ ), and NR2C $(135 \mathrm{kDa}$ ) subunits. A representative Western blot $(A)$ demonstrates the decrease in full-length $\mathrm{NR2A} / 2 \mathrm{~B}(170 \mathrm{kDa})(p=0.016$ for $30 \mathrm{vs} 0 \mathrm{~min} ; n=13)$ as well as the simultaneous increase in levels of a $115 \mathrm{kDa}$ species ( $0 \mathrm{vs} 30 \mathrm{~min}=0.0044 ; n=12$ ). This blot was overexposed to show more clearly both the breakdown product and the decrease of full-length NR2A/2B. The increase in the LMW species was inhibited by inclusion of $100 \mu \mathrm{M}$ MK- 801 in the treatment conditions $(p=0.0135$ MK-801 vs $30 \mathrm{~min} ; n=12)$ (C). Inclusion of $100 \mu \mathrm{M}$ MK-801 in the treatment conditions also prevented the decrease of full-length NR2A/2B (MK-801 vs $30 \mathrm{~min}=0.0004$; $n=12$ ). NR2 immunoreactivity was quantitated as a percentage of the MK-801 control condition.

30 min glutamate and glycine condition compared with cells protected by MK-801, suggesting that the cleavage is not merely an effect of cell lysis (data not shown).

To determine the selectivity of NR2 subunit cleavage, samples were probed for NR1 and actin, which are both poor calpain substrates (Guttmann et al., 2001, 2002). Neither actin (Fig. 3A) nor NR1 (Fig. 3B) was degraded. These data suggest that at least one NR2 subunit is rapidly cleaved in the C-terminal region in hippocampal neurons after NMDA receptor stimulation and that this is not a generalized effect on all proteins. Because the $\mathrm{N}$-terminal antibody recognizes both NR2A and NR2B (which have similar molecular weights), we sought to identify which NR2 subunit was cleaved in this process. An NR2B-specific antibody demonstrated a $45 \%$ decrease of full-length NR2B immunoreactivity ( $p=0.0021,30 \mathrm{~min}$ vs MK-801; $p=0.0020,30$ vs 0 $\min ; n=7$ ) (Fig. $3 C, D$ ) with the same time course but greater in amount than the decrease of full-length NR2A/2B immunoreactivity (22\%) (Fig. 2). In contrast, no change was seen in NR2A levels using a subunit-selective antibody to the $\mathrm{C}$ terminus of NR2A (Fig. 3E). This identifies NR2B as the major subunit cleaved after NMDA receptor activation. Decreases in levels of NR2B immunoreactivity and an increase in the levels of the LMW fragment were also produced by incubation with lower levels of glutamatergic stimulation (as low as $1 \mu \mathrm{M}$ glutamate) and matched the cleavage of spectrin by calpain in a glutamate doseresponse curve (Fig. $3 F$ ).

No shorter fragment was observed using the NR2B-selective antibodies, suggesting either that the product of NR2B cleavage is not stable in neurons or that the cleavage of NR2B occurs within the epitope of the 2B-selective antibody (amino acids 984-1104), roughly the expected site of cleavage on the basis of the LMW species in Figure 2. We sought to confirm that the cleavage was within the epitope of the NR2B antibody by comparing the molecular weight of the LMW fragment with truncated forms of 

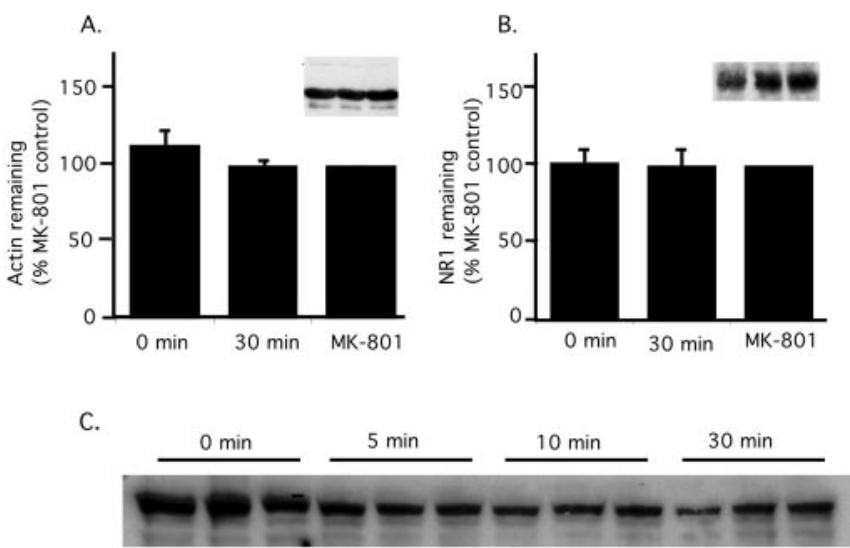

D.

E.
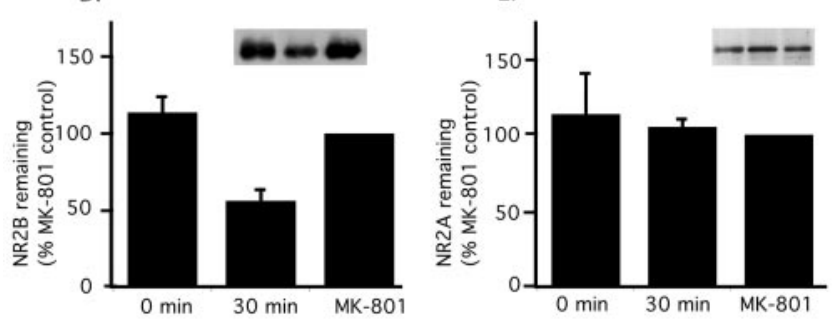

F.

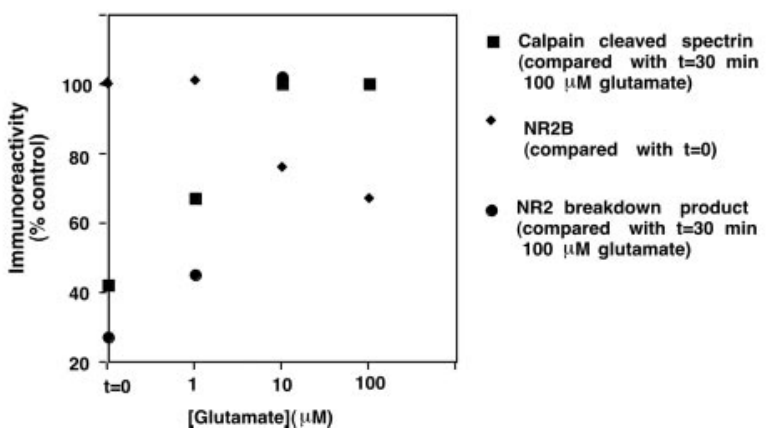

Figure 3. Selective cleavage of NR2B subunits. To determine which subunits were degraded after activation of calpain by the NMDA receptor, samples treated with $100 \mu \mathrm{m}$ glutamate and glycine in the presence or absence of $100 \mu \mathrm{m}$ MK-801 were immunoblotted with NR1 ( $B$ ), NR2A $(E)$, and $\mathrm{NR2B}(C, D)$ selective $($-terminal antibodies as well as with an anti-actin $(A)$ antibody. Representative Western blots (shown as insets for $0 \mathrm{~min}, 30 \mathrm{~min}$, and MK-801 control in $A, B, D$, $E$ ) and bar graphs for each are shown. Actin showed no loss of immunoreactivity under the treatment conditions $(A)$ nor did NR1 ( $B)$. NR2B showed a $45 \%$ decrease of immunoreactivity in the 30 min condition compared with 0 min and samples including MK-801 (C,D) ( $p=0.0021$ vs MK- $801 ; p=0.0020$ vs 0 min; $n=7$ ). NR2A ( $E$ ) showed no decrease of immunoreactivity in the treatment condition. Decrease of NR2B subunit immunoreactivity and the increase of the LMW form was also produced by lower levels of agonist and matched the production of calpaincleaved spectrin in glutamate dose-response curves $(F)$.

NR2 subunits produced in transfected HEK293 cells (Fig. 4A). When we compared the LMW form with NR2A subunits truncated at amino acids 895 (104 kDa), 1051 (120 kDa), 1279 (144 $\mathrm{kDa})$, and NR2B lacking amino acids $1038-1370(127 \mathrm{kDa})$, or truncated at amino acid $1170(133 \mathrm{kDa})$, the LMW form was $\sim 1030$ amino acids (Fig. $4 B$ ). This confirms that the LMW fragment is likely not to be recognized by the NR2B selective antibody. We also compared the molecular weight of the LMW fragment with that produced by cleavage of NR2B by calpain in vitro (Fig. $4 A, B$ ). Although NR2B was cleaved by calpain in vitro at several sites in the $\mathrm{C}$-terminal region, the size of the smallest product was identical to that produced in hippocampal neurons,
A.

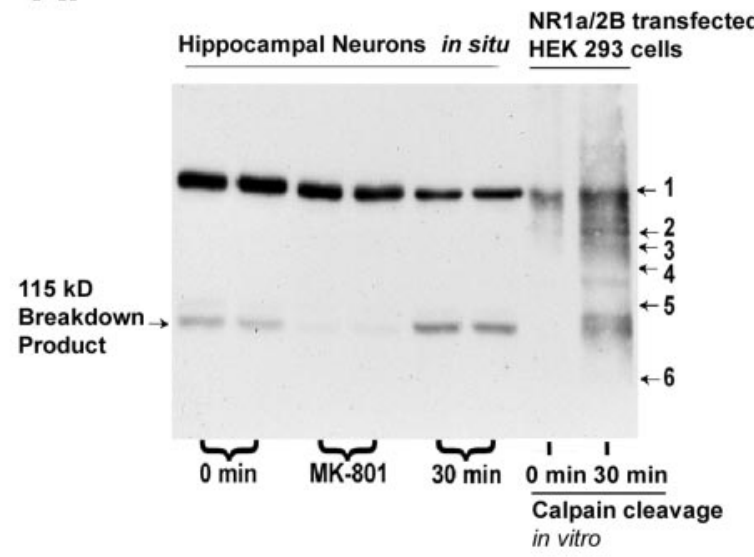

B.

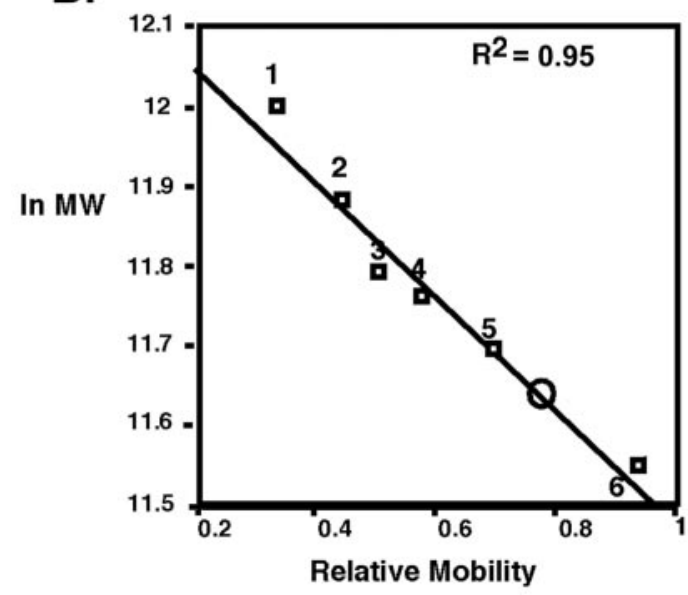

Figure 4. Characterization of the size of the NR2A/2B breakdown fragment. Neurons were treated with agonists as described in Materials and Methods and compared with NR2B cleaved in vitro with calpain (from receptors produced in HEK293 cells) using Western blotting with the $\mathrm{N}$-terminal antibody. The size of the LMW breakdown product in neurons matched that of the smallest calpain-generated fragment of NR2B produced by in vitro cleavage. The LMW fragment was also compared on parallel blots with full-length NR2A and five C-terminally truncated forms of NR2A or NR2B of known size $(A, 1-6): 1=$ full-length NR2A $(170 \mathrm{kDa}) ; 2=\mathrm{NR} 2 \mathrm{~A} 1279$ $(144 \mathrm{kDa}) ; 3=\mathrm{NR} 2 \mathrm{~B} 1170(133 \mathrm{kDa}) ; 4=\mathrm{NR} 2 \mathrm{Bdel} 1034-1370(127 \mathrm{kDa}) ; 5=\mathrm{NR} 2 \mathrm{~A} 1051$ (120 $\mathrm{kDa}) ; 6=\mathrm{NR} 2 \mathrm{~A} 895(104 \mathrm{kDa})$. The mobility plot $(B)$ suggests that the LMW form $(\bigcirc)$ has an MW of $114 \mathrm{kDa}$ or $\sim 1030$ amino acids. It is also of note that the LMW fragment can be present under basal conditions to some degree ( $A$, first 2 lanes) in a manner that is inhibited by inclusion of MK-801.

suggesting that calpain is the protease giving rise to this fragment. $\mathrm{NR} 1 / 2 \mathrm{~B}$ receptors cleaved by calpain in vitro retained the ability to bind ${ }^{125} \mathrm{I}-\mathrm{MK} 801$ (99.7 $\pm 20.1 \%$ of control), suggesting that, as found in other reports, receptors containing NR2B subunits of this size should be active (Liao et al., 2001).

We also sought to confirm directly that calpain was the protease involved in NR2 subunit degradation in cultured hippocampal neurons. CalI3 ( $p=0.048$ by ANOVA; $n=7 ; p=$ 0.0021 Call3 vs $30 \mathrm{~min}$ ) but not inhibitors of caspases or cathep$\sin (p>0.1 ; n=5-6$ for both) prevented the change in levels of full-length NR2B (Fig. 5A). Similarly, using the N-terminal antibody (A6475), degradation of total NR2A/2B was inhibited by CalI3 ( $p=0.028$ by ANOVA; $n=10 ; p=0.018$ CalI 3 vs $30 \mathrm{~min}$ ) but not inhibitors of caspases or cathepsin $(p>0.1 ; n=9-10$ for 


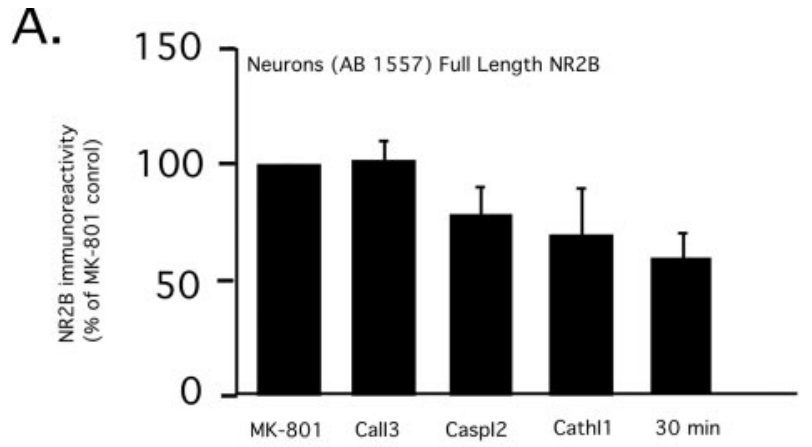

B.
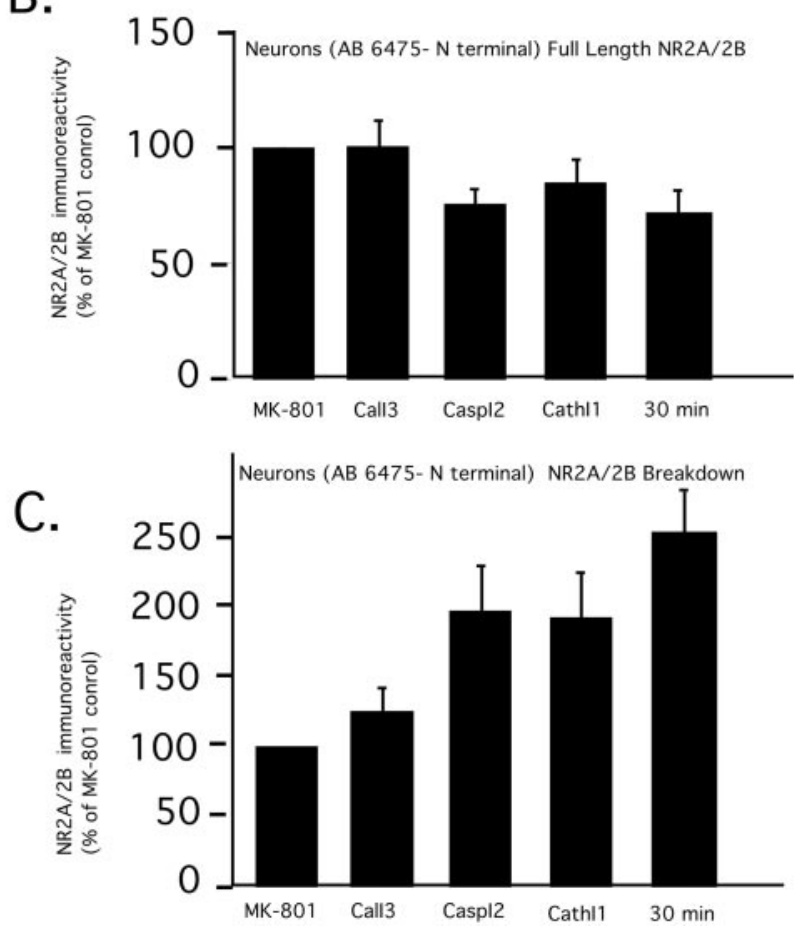

Figure 5. Identification of the protease involved in NR2B subunit cleavage. Neurons treated with $100 \mu \mathrm{m}$ glutamate and glycine for $30 \mathrm{~min}$ in the presence of calpain inhibitor III (Call3), caspase inhibitor II (Caspl2), or cathepsin inhibitor I (Cathl1). The inhibition of calpain ( $n=7$; $p=0.002$; Call3 vs $30 \mathrm{~min}$ ) but not caspases or cathepsin ( $p>0.1 ; n=5-6$ for both) prevented the decrease of full-length NR2B $(A)$. Likewise, using the N-terminal antibody, degradation of total $\mathrm{NR} 2 \mathrm{~A} / 2 \mathrm{~B}$ was significantly inhibited by the calpain inhibitor $(n=10 ; p=0.02$ Call3 vs $30 \mathrm{~min})(B)$ as was the increased appearance of the LMW fragment $(C)(n=9 ; p=$ 0.004 (alll3 vs $30 \mathrm{~min}$ ). Levels of the LMW form were normalized to the breakdown product in the MK-801 control such that increases in levels appear as increases over the control level of $100 \%$.

both) (Fig. 5B). We observed less of an appearance of the LMW fragment of NR2A/2B with the CalI3 ( $p=0.0022$ by ANOVA; $n=9 ; p=0.004$ Call3 vs $30 \mathrm{~min}$ ) (Fig. 5 C). Caspase and cathepsin inhibition did not significantly reverse production of the LMW fragment $(p>0.10 ; n=7-8)$. These data show that calpain is the major protease leading to the decrease in levels of full-length NR2B and total NR2A/2B and the increases in the truncated form of NR2.

\section{Cleavage of NR2B in heterologous systems}

Cleavage of NR2B is consistent with in vitro data, but only NR2A has been shown to be degraded in situ in heterologous systems ( $\mathrm{Bi}$ et al., 1998; Guttmann et al., 2001, 2002). Thus, we tested whether NR2B also might be cleaved by calpain in other cellular models.

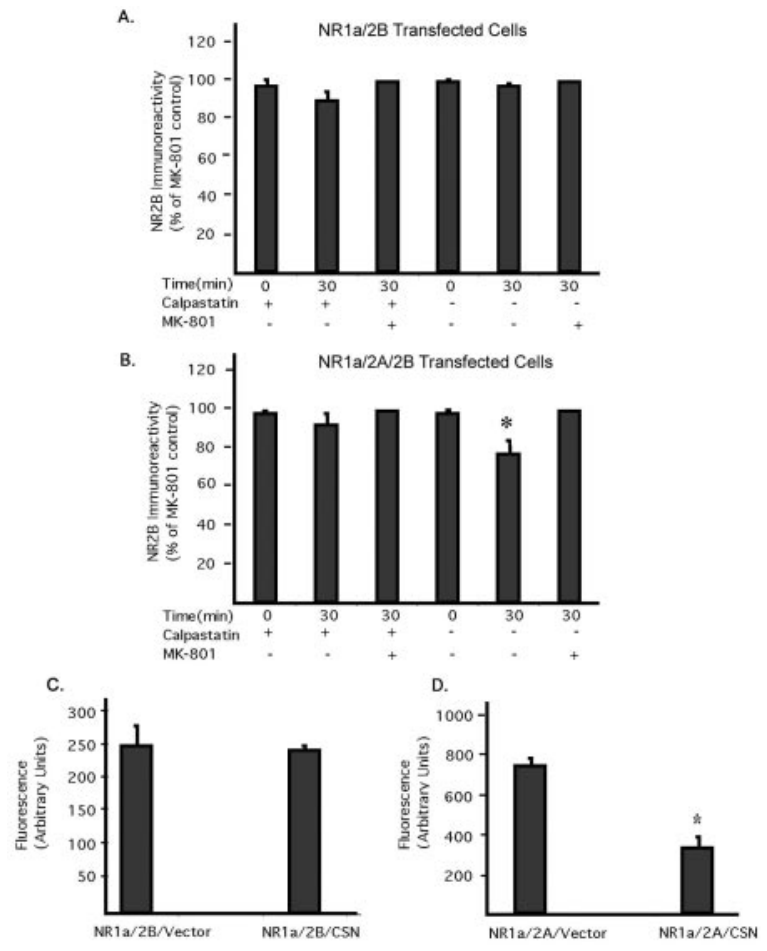

Figure 6. Cleavage of NR2B in heterologous systems. NR1a/2B-transfected HEK293 cells that were cotransfected with calpastatin (CSN) or control vector showed no change in NR2B immunoreactivity after 30 min agonist treatment with or without inclusion of MK-801 ( $A$ ). Cells transfected with NR1a/2A/2B, however, showed decreased NR2B immunoreactivity after 30 min of agonist treatment ( $p=0.024 ; n=5$ ) that was inhibited by cotransfection with calpastatin and by inclusion of MK- 801 in the treatment conditions $(B)$. Calpain activity was measured in NR1a/2A- or NR1a/2B-transfected cells that were cotransfected with calpastatin or control vector. Cells were treated by the stimulation of NMDA receptors with $100 \mu \mathrm{m}$ of both glutamate and glycine for $40 \mathrm{~min}$, and the amount of fluorescence was quantitated. Agonist treatment of NR1a/2B-transfected cells compared with calpastatin-cotransfected cells resulted in no significant difference in fluorescence ( $C$, whereas treatment of NR1a/2A-transfected cells resulted in increased cleavage of the substrate Suc-LLVY-AMC as shown by increased fluorescence $\left.{ }^{*} p=0.004 ; n=3\right)(D)$.

When HEK293 cells were transfected with NR1/2B and treated with glutamate and glycine, NR2B was not degraded (Fig. 6A). In contrast, in NR1/2A/2B-transfected cells, NR2B was degraded $(p=0.0237 ; n=5)$ as demonstrated by a decrease of full-length NR2B immunoreactivity using the NR2B-specific antibody (Fig. $6 B)$. This effect was inhibited by cotransfection of calpastatin, the specific endogenous calpain inhibitor. This appeared to reflect the failure of NR2B-containing receptors to activate calpain after agonist application because no cleavage of the calpain substrate Succ-LLVY-AMC was found in NR1/2B-transfected cells, whereas NR1/2A transfection led readily to Succ-LLVY-AMC degradation $(p=0.0053 ; n=3)$ (Fig. $6 C, D)$. This suggests that in transfected cell models, as in cultured neurons, NR2B can be cleaved by calpain, but only if the NR2A subunit is present to facilitate calpain activation.

\section{Localization of cleaved NR2B}

We also sought to establish the intracellular or extracellular localization of the LMW fragment produced by NR2A/2B cleavage. When hippocampal neurons were treated with glutamate and glycine, and cell surface components were labeled with NHSbiotin, the total cellular lysate contained increasing levels of the $115 \mathrm{kDa}$ breakdown product with time, whereas full-length levels declined in the total lysate (Fig. 7A). Seventy to eighty percent of 


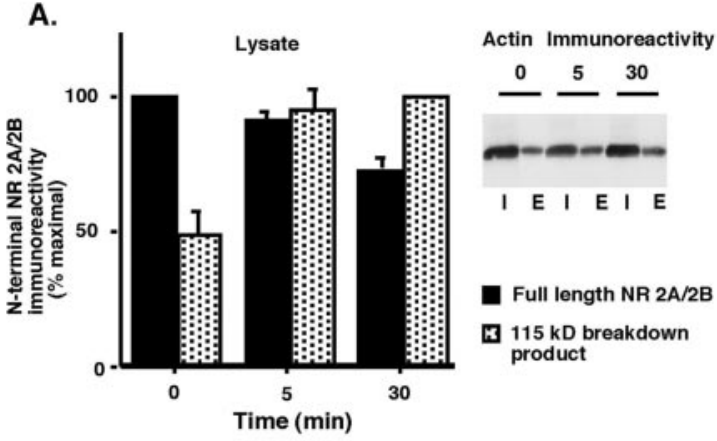

B.

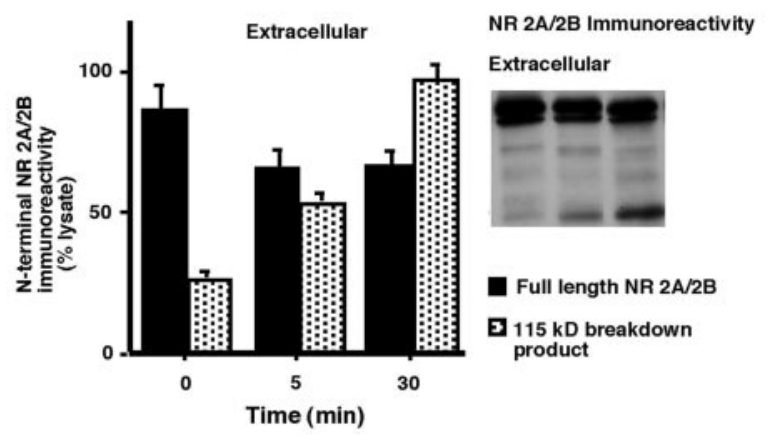

C.

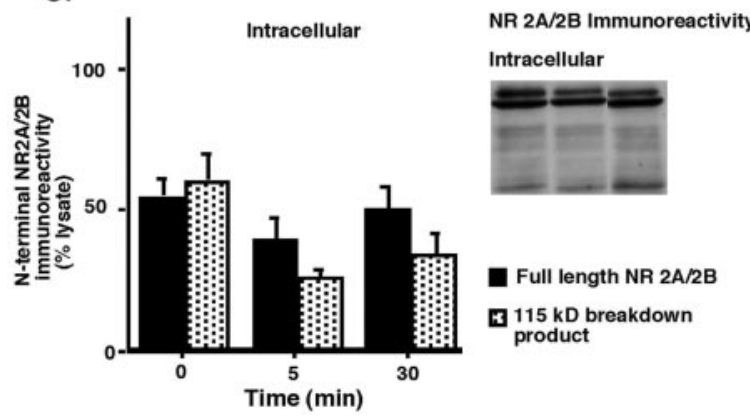

Figure 7. Localization of cleaved NR2B. Hippocampal neuron cultures were preincubated with $100 \mu \mathrm{m}$ glutamate and glycine for 0,5 , or $30 \mathrm{~min}(n=4)$. Cells were then labeled with NHS-biotin under non-lytic conditions, and the extracellular and intracellular fragments were separated. Thirty micrograms of total protein were separated by SDS-PAGE and immunoblotted with an $\mathrm{N}$-terminal antibody for NR2. The amount of immunoreactivity in the lysate was quantified as a percentage of the amount of full-length NR2A/2B found at the 0 min time point or the amount of the LMW fragment found in the 30 min time point. For extracellular and intracellular fractions, the immunoreactivity was quantified as a percentage of the amount in the total lysate at that time point. Over time, full-length NR2A/2B in both the total lysate $(A)$ and extracellular $(B)$ fractions decreased, and the level of the LMW fragment in the extracellular fraction increased with time $(B)$. So that we may assume preservation of membrane integrity in biotinylation of these cultures, samples were probed with an anti-actin antibody to confirm that actin remains primarily in the intracellular fraction; $70-80 \%$ of the actin was found in the intracellular fraction (I) at 0,5 , and 30 min as shown by a representative blot $(A)$. The intracellular full-length NR2A/2B fraction does not significantly change during treatment ( $C$ ). Likewise, the small amount of the LMW fragment found in the intracellular fraction remains relatively constant; however, the percentage of LMW fragment in the intracellular fraction decreased over time because the amount of the LMW fragment increased with time in the total lysate fraction. In these experiments the amount of full-length extracellular NR2A/2B decreased from $88 \pm 4$ to $51 \pm 5 \%$ of the total extracellular NR2A/2B over the 30 min incubation. Because each fraction is normalized to the level in the lysate, the total of intracellular and extracellular fractions can be slightly different from $100 \%$, reflecting small nonlinearities in quantification across substantially different optical density values.

actin (a marker of intracellular protein) was found in the intracellular fraction (Fig. 7A) at all times after agonist activation, demonstrating that the treatment conditions do not cause cell lysis. In the same experiments, the increase in the LMW fragment was found in the biotinylated fraction, characteristic of a cell surface location ( $p=0.0002$ ). The LMW fragment increased in the cell surface fraction within $5 \mathrm{~min}$ of agonist application (Fig. $7 B$ ). In contrast, only a small amount of LMW fragment was present in the intracellular fraction, and its level remained constant over the 30 min time course (Fig. 7C). Full-length NR2A/2B declined over the time course, decreasing from the extracellular fraction ( $p=0.045$ ). Approximately $61 \%$ of the full-length NR2 immunoreactivity was found in the extracellular fraction under basal conditions. The extracellular level of full-length NR2A/2B declined from $88 \pm 4$ to $51 \pm 5 \%$ of the total extracellular NR2A/2B in these experiments, suggesting that $37 \%$ of the NR2 immunoreactivity was cleaved in these experiments. These data suggest that activation of the NMDA receptor in neurons leads to cleavage of the NMDA receptor by calpain to produce large potentially active fragments that remain on the cell surface.

\section{Cleavage of NR2 in models of ischemia}

Because calpain appears to cleave NR2B rapidly in cell culture models of excitotoxicity, we then sought to determine whether such events occur in animal models of human excitotoxic diseases such as ischemia. We examined the possibility of calpain cleavage of NR2A/2B subunits in hippocampus after transient ischemia. In this model, which uses a transient bilateral carotid occlusion, calpain is activated rapidly and in a delayed manner 24-48 hr after initial ischemia (Neumar et al., 2001). When we examined levels of NR2 in ischemic and control hippocampus $48 \mathrm{hr}$ after transient ischemia using Western blotting with the $\mathrm{N}$-terminal antibody, this antibody demonstrated increased levels of a low molecular weight form of NR2 in ischemic tissue (Fig. $8 A, C)(p=0.002)$, matching that produced by calpain in cell culture, as well as an increase in the ratio of LMW form to full-length NR2A/2B after ischemia (Fig. $8 \mathrm{~B}$ ) $(p=0.002)$. Thus, cleavage of the NMDA receptor by calpain appears to occur in excitotoxic events of the brain as well as in cell culture models.

\section{Discussion}

The present study demonstrates NMDA receptor activationinduced cleavage of the NR2 subunit by calpain in neurons after glutamatergic stimulation. The major cleaved subunit in cultured hippocampal neurons appears to be NR2B, with no detectable cleavage of NR2A and no cleavage of NR1. In addition, the cleavage of NR2B creates a fragment that remains on the extracellular surface after its production. This fragment should be active on the basis of predictions from its molecular weight and the lack of effect of calpain cleavage on ${ }^{125} \mathrm{I}-\mathrm{MK}-801$ binding to NR1/2B receptors (Liao et al., 2001). This suggests that novel, active cleavage products of the NR2B subunit are created during excitotoxic conditions. Cleavage of the C-terminal region by calpain would remove sites critical for NMDA receptor modulation by protein kinase C (S1303 and S1323), tyrosine kinase (many sites), and calcium-calmodulin-dependent kinase (S1303) (Omkumar et al., 1996; Liao et al., 2001). Because this region also contains the binding site for postsynaptic density-95 (PSD-95), calpaincleaved NR2B subunits would no longer be attached to PSD-95, an association thought to be involved in NR2B turnover (Roche et al., 2001). Thus, calpain cleavage would create NR2B subunits that are no longer under the control of modulatory elements, similar to effects of calpain noted previously on protein kinase C in long-term potentiation (Hrabetova and Sacktor, 1996). These receptors could still be modulated by sites in coassembled subunits (NR1, NR2A), however, and still may be attached to 
A.

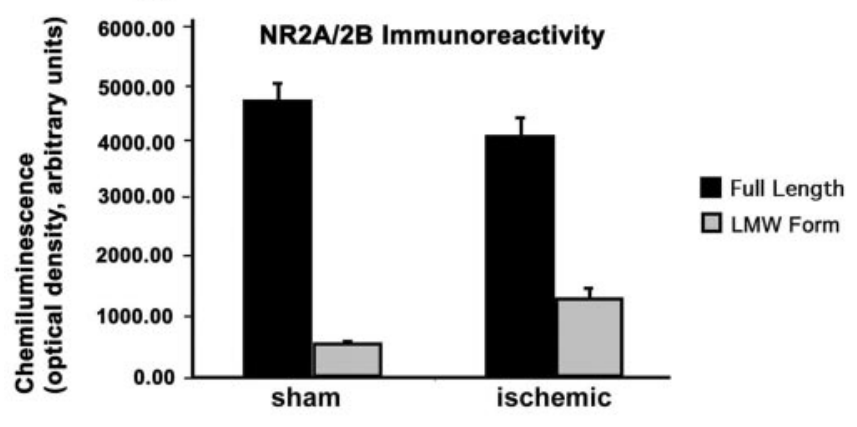

B.

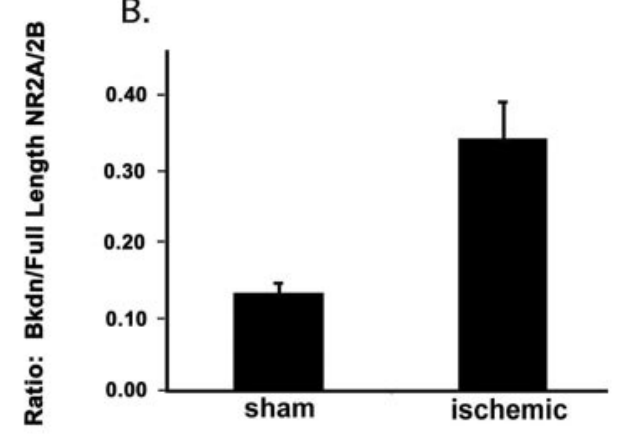

C.

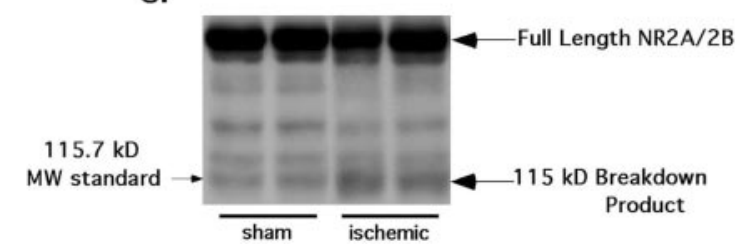

Figure 8. Cleavage of NR2 After transient ischemia. The hippocampus of control and ischemic rats was examined by Western blotting with an N-terminal antibody to NR2. Samples were obtained $48 \mathrm{hr}$ after either $10 \mathrm{~min}$ transient forebrain ischemia or sham operation. In ischemic samples, this antibody demonstrated greater levels of a low molecular weight form of NR2 $(A)$, matching that produced by calpain in neuronal culture ( $p=0.002)$. There was also an increase in the ratio of the LMW form to full-length NR2A/2B in the ischemic samples $(B)(n=7)(p=$ 0.002 ). A representative Western blot ( $C$ comparing NR2A/2B full-length and breakdown product in synaptosomal fractions of sham and ischemic hippocampus $48 \mathrm{hr}$ after ischemia shows the presence of an LMW fragment in ischemic samples.

PSD-95 by coassembled NR2A. This would create heteromeric receptors with potentially complex modulation and turnover properties (Sheng et al., 1994).

The present results differ from our results in transfected cells in several ways. First, in NR1a/2A-transfected cells, NR2A subunits are readily cleaved after stimulation with glutamate and glycine (Guttmann et al., 2001, 2002), whereas NR2B cleavage in HEK293 cells appears to require cotransfection with NR2A. In contrast, activation of NR2A-containing receptors appears important for calpain activation, but NR2A itself is not cleaved in our neuronal model (Guttmann et al., 2001, 2002). This suggests that other neuronal factors prevent NR2A from being readily cleaved. Such factors may include differing levels of phosphorylation between NR2A and NR2B, because phosphorylation alters calpain cleavage of NR2 subunits in vitro (Bi et al., 1998a,b). NR2A subunits are also preferentially associated with synapses in neuronal culture, and synaptic receptors may be less accessible to proteolytic degradation (Stocca and Vicini, 1998; Tovar and Westbrook, 1999; Li et al., 2002); however, the role of NR2A in activation of calpain (implying a synaptic activation of calpain) and the presence of cleaved NR2B in the synaptosomal fraction of ischemic animals suggest that simple synaptic versus extrasynaptic localization cannot explain the present data. The present data are overall more consistent with cleavage of synaptic NR2B, possibly when coassembled with NR1 and NR2A. Additional experiments may explore these possibilities. Interestingly, inhibition of the proteosome over longer time periods in conjunction with synaptic activation of NMDA receptors preferentially leads to preservation of NR2B with little change in NR2A (Ehlers, 2003). This suggests the presence of mechanisms stabilizing NR2A from multiple proteases.

In addition, cleavage of NR2 subunits in transfected cells is a degradative process because calpain-produced cleavage products of NR2A were not observed, whereas calpain-generated products of NR2 are found in neurons (Guttmann et al., 2002). Neurons may make stabilizing "factors" (e.g., kinases) that allow persistence of truncated forms of the NR2 subunit, or they could have more tightly controlled proteolytic activity for receptor degradation subsequent to calpain cleavage. Alternatively, the stable fragment in neurons is a component of NR2B rather than NR2A and thus may be inherently more stable than the cleavage products of NR2A predicted from heterologous systems. Finally, the endocytic mechanisms and internalization processes that cause rapid NR2 destruction in HEK293 cells may be substantially slower in neurons. Neurons, and particularly dendrites (where NMDA receptors are located), contain structural features that may impede rapid turnover of proteins in response to a dramatic stimulus. Clathrin-mediated endocytosis is restricted to specialized locations in dendrites (Blanpied et al., 2002). If NR2 receptors are internalized through endosomes, then the relative lack of endosomes in single dendrites would prevent rapid internalization of large quantities of receptor, particularly under excitotoxic conditions in which protein degradation by calpain would be increased and cytoskeletal damage is present (Cooney et al., 2002; Buddle et al., 2003). Experiments directly testing these possibilities may determine the exact reason for differences between neurons and HEK293 cells.

One unexpected finding of the present study was that NR2Acontaining receptors appear to activate calpain more readily than NR2B-containing receptors in transfected cells and possibly in neurons. This may reflect the greater rise in calcium and greater opening probability of NR2A-containing receptors compared with NR2B-containing receptors in transfected cells (Grant et al., 1998; Chen et al., 1999). When neuronal calpain activity has been measured, it is typically highest early in development, with subsequent decline. This does not clearly match the developmental pattern of NR2 subunits, with NR2B representing the major prenatal subunit, and increasing levels of NR2A over the first few weeks of life in the rodent. Because measurements of calpain activity are frequently made on the basis of cleavage of distinct protein substrates, the temporal course of calpain development may reflect both enzymatic and substrate considerations. Our data showing a greater role of NR2A in calpain activation are consistent with this possibility.

In most experimental paradigms, calpain cleavage of NMDA receptor subunits in neurons has been noted after prolonged agonist stimulation, and no N-terminal fragments have been characterized (Bi et al., 1998a,b). In the present study, we have identified a stable $\mathrm{N}$-terminal fragment and demonstrated rapid cleavage of the NR2B subunit ( $<5 \mathrm{~min}$ ). Although conditions used here are excitotoxic, the present changes are too rapid to represent purely cell death responses, and the cells are not lysed 
by this treatment as indicated by the lack of actin labeling by NHS-biotin. In addition, the changes that we note also begin to occur at lower levels of glutamatergic stimulation $(1 \mu \mathrm{M})$ than used in fully excitotoxic conditions, and the LMW fragment appears to a small degree in basal levels of untreated cultures (Stout et al., 1998; Hashimoto et al., 2002). Previously, calpain has been demonstrated to mediate synaptic remodeling and restructuring in the period after glutamatergic stimulation (Faddis et al., 1997). The present results suggest that calpainmediated cleavage of the NR2B subunit may be involved in early events of excitotoxicity and neuronal remodeling after glutamatergic stimulation, including that noted in ongoing synaptic activity.

Finally, we demonstrate that the calpain-generated fragments of the NR2 subunit are also generated in vivo after transient forebrain ischemia. Such receptors could potentially contribute to postischemic cytotoxicity and delayed neuronal death. NMDA receptors with novel properties have been reported previously in animal models of excitotoxicity (Lieberman and Mody, 1999). More detailed analysis of these paradigms is needed to determine whether the calpain-generated forms of NMDA receptor noted here represent these unusual physiologic forms.

\section{References}

Adamec E, Beermann ML, Nixon RA (1998) Calpain I activation in rat hippocampal neurons in culture is NMDA receptor selective and not essential for excitotoxic cell death. Brain Res Mol Brain Res 54:35-48.

Anegawa NJ, Lynch DR, Verdoorn TA, Pritchett DB (1995) Transfection of $\mathrm{N}$-methyl-D-aspartate receptors in a nonneuronal cell line leads to cell death. J Neurochem 64:2004-2012.

Bi R, Bi X, Baudry M (1998a) Phosphorylation regulates calpain-mediated truncation of glutamate ionotropic receptors. Brain Res 797:154-158.

Bi X, Rong Y, Chen J, Dang S, Wang Z, Baudry M (1998b) Calpainmediated regulation of NMDA receptor structure and function. Brain Res 790:245-253.

Blanpied TA, Scott DB, Ehlers MD (2002) Dynamics and regulation of clathrin coats at specialized endocytic zones of dendrites and spines. Neuron 36:435-449.

Buddle M, Eberhardt E, Ciminello LH, Levin T, Wing R, DiPasquale K, RaleySusman KM (2003) Microtubule-associated protein 2 (MAP2) associates with the NMDA receptor and is spatially redistributed within rat hippocampal neurons after oxygen-glucose deprivation. Brain Res 978:38-50.

Chen N, Luo T, Raymond LA (1999) Subtype-dependence of NMDA receptor channel open probability. J Neurosci 19:6844-6854.

Cooney JR, Hurlburt JL, Selig DK, Harris KM, Fiala JC (2002) Endosomal compartments serve multiple hippocampal dendritic spines from a widespread rather than a local store of recycling membrane. J Neurosci 22:2215-2224.

Dingledine R, Borges K, Bowie D, Traynelis SF (1999) The glutamate receptor ion channels. Pharmacol Rev 51:7-61.

Ehlers MD (2003) Activity level controls postsynaptic composition and signaling via the ubiquitin-proteasome system. Nat Neurosci 6:231-242.

Faddis BT, Hasbani MJ, Goldberg MP (1997) Calpain activation contributes to dendritic remodeling after brief excitotoxic injury in vitro. J Neurosci 17:951-959.

Gallagher MJ, Huang H, Grant ER, Lynch DR (1997) The NR2B-specific interactions of polyamines and protons with the $N$-methyl-D-aspartate receptor. J Biol Chem 272:24971-24979.

Gionet TX, Warner DS, Verhaegen M, Thomas JD, Todd MM (1992) Effects of intra-ischemic blood pressure on outcome from 2-vessel occlusion forebrain ischemia in the rat. Brain Res 586:188-194.

Grant ER, Basckai BJ, Gallagher MJ, Kendrick SL, Pritchett DB, Kricka L, Pleasure DP, Lynch DR (1997) Heteromeric NMDA receptor calcium responses in transfected HEK-293 cells. J Biol Chem 272:647-656.

Grant ER, Bacskai BJ, Anegawa NJ, Pleasure DE, Lynch DR (1998) Oppos- ing contributions of NR1 and NR2 to protein kinase C modulation of NMDA receptors. J Neurochem 71:1471-1481.

Guttmann RP, Elce JS, Bell PD, Isbell JC, Johnson GV (1997) Oxidation inhibits substrate proteolysis by calpain I but not autolysis. J Biol Chem 272:2005-2012.

Guttmann RP, Baker DL, Seifert KS, Cohen A, Coulter DA, Lynch DR (2001) Specific proteolysis of the NR2 subunit at multiple sites by calpain. J Neurochem 78:1083-1093.

Guttmann RP, Sokol S, Baker DL, Simpkins KL, Dong Y, Lynch DR (2002) Proteolysis of the $N$-methyl-D-aspartate receptor by calpain in situ. J Pharmacol Exp Ther 302:1023-1030.

Hashimoto R, Hough C, Nakazawa T, Yamamoto T, Chuang DM (2002) Lithium protection against glutamate excitotoxicity in rat cerebral cortical neurons: involvement of NMDA receptor inhibition possibly by decreasing NR2B tyrosine phosphorylation. J Neurochem 80:589-597.

Hell JW, Westenbroek RE, Breeze LJ, Wang KK, Chavkin C, Catterall WA (1996) $\mathrm{N}$-methyl-D-aspartate receptor-induced proteolytic conversion of postsynaptic class C L-type calcium channels in hippocampal neurons. Proc Natl Acad Sci USA 93:3362-3367.

Hrabetova S, Sacktor TC (1996) Bidirectional regulation of protein kinase $\mathrm{M} \zeta$ in the maintenance of long-term potentiation and long-term depression. J Neurosci 16:5324-5333.

Johnson GV, Guttmann RP (1997) Calpains: intact and active? BioEssays 19:1011-1018.

Kim E, Cho K-O, Rothschild A, Sheng M (1996) Heteromultimerization and NMDA receptor-clustering activity of chapsyn-110, a member of the PSD-95 family of proteins. Neuron 17:103-113.

Li B, Chen N, Luo T, Otsu Y, Murphy TH, Raymond LA (2002) Differential regulation of synaptic and extra-synaptic NMDA receptors. Nat Neurosci 5:833-834.

Liao GY, Wagner DA, Hsu MH, Leonard JP (2001) Evidence for direct protein kinase-C mediated modulation of $\mathrm{N}$-methyl-D-aspartate receptor current. Mol Pharmacol 59:960-964.

Lieberman DN, Mody I (1999) Properties of single NMDA receptor channels in human dentate gyrus granule cells. J Physiol (Lond) 518:55-70.

Lynch DR, Guttmann RP (2002) Excitotoxicity: perspectives based on NMDA receptor subtypes. J Pharmacol Exp Ther 300:717-723.

Lynch DR, Anegawa NJ, Verdoorn T, Pritchett DB (1994) N-methyl-Daspartate receptors: different subunit requirements for binding of glutamate antagonists, glycine antagonists, and channel-blocking agents. Mol Pharmacol 45:540-545.

Lynch DR, Lawrence JJ, Lenz S, Anegawa NJ, Dichter M, Pritchett DB (1995) Pharmacological characterization of heterodimeric NMDA receptors composed of NR1a and 2B subunits: differences with receptors formed from NR 1a and 2A. J Neurochem 64:1462-1468.

Nakanishi S (1992) Molecular diversity of glutamate receptors and implications for brain function. Science 258:597-603.

Neumar RW, Meng FH, Mills AM, Xu YA, Zhang C, Welsh FA, R. S (2001) Calpain activity in the rat brain after transient forebrain ischemia. Exp Neurol 170:27-35.

Omkumar RV, Kiely MJ, Resenstein AJ, Min K-T, Kennedy MB (1996) Identification of a phosphorylation site for calcium/calmodulindependent protein kinase II in the NR2B subunit of the N-methyl-Daspartate receptor. J Biol Chem 271:31670-31678.

Roberts-Lewis JM, Savage MJ, Marcy VR, Pinsker LR, R. S (1994) Immunolocalization of calpain I-mediated spectrin degradation to vulnerable neurons in the ischemic gerbil brain. J Neurosci 14:3934-3944.

Roche KW, Standley S, McCallum J, Dune Ly C, Ehlers MD, Wenthold RJ (2001) Molecular determinants of NMDA receptor internalization. Nat Neurosci 4:794-802.

Sheng M, Cummings J, Roldan LA, Jan YN, Jan LY (1994) Changing subunit composition of heteromeric NMDA receptors during development of rat cortex. Nature 368:144-147.

Sims KD, Straff DJ, Robinson MB (2000) Platelet-derived growth factor rapidly increases activity and cell surface expression of the EAAC1 subtype of glutamate transporter through activation of phosphatidylinositol 3-kinase. J Biol Chem 275:5228-5237.

Smith ML, Bendek G, Dahlgren N, Rosen I, Wieloch T, Siesjo BK (1984) Models for studying long-term recovery following forebrain ischemia in the rat. 2. A 2-vessel occlusion model. Acta Neurol Scand 69:385-401.

Sprengel R, Suchanek B, Amico C, Brusa R, Burnashev N, Rozov A, Hvalby O, 
Jensen V, Paulsen O, Andersen P, Kim JJ, Thompson RF, Sun W, Webster LC, Grant SG, Eilers J, Konnerth A, Li J, McNamara JO, Seeburg PH (1998) Importance of the intracellular domain of NR2 subunits for NMDA receptor function in vivo. Cell 92:279-289.

Stocca G, Vicini S (1998) Increased contribution of NR2A subunit to synaptic NMDA receptors in developing rat cortical neurons. J Physiol (Lond) 507:13-24.

Stout AK, Raphael HM, Kanterewicz BI, Klann E, Reynolds IJ (1998) Glutamate-induced neuron death requires mitochondrial calcium uptake. Nat Neurosci 1:366-373.

Tovar KR, Westbrook GL (1999) The incorporation of NMDA receptors with a distinct subunit composition at nascent hippocampal synapses in vitro. J Neurosci 19:4180-4188.

Vanderklish P, Bednarski E, Lynch G (1996) Translational suppression of calpain blocks long-term potentiation. Learn Mem 3:209-217.
Wang KK (2000) Calpain and caspase: can you tell the difference? Trends Neurosci 23:20-26.

Wilcox KS, Buchhalter J, Dichter MA (1994) Properties of inhibitory and excitatory synapses between hippocampal neurons in very low density cultures. Synapse 18:128-151.

Williams K (1993) Ifenprodil discriminates subtypes of the $N$-methyl-Daspartate receptor: selectivity and mechanisms at recombinant heteromeric receptors. Mol Pharmacol 44:851-859.

Zhang C, Siman R, Xu YA, Mills AM, Frederick JR, Neumar RW (2002) Comparison of calpain and caspase activities in the adult rat brain after transient forebrain ischemia. Neurobiol Dis 10:289-305.

Zheng X, Zhang L, Wang AP, Bennett MV, RS. Z (1999) Protein kinase C potentiation of $N$-methyl-D-aspartate receptor activity is not mediated by phosphorylation of $N$-methyl-D-aspartate receptor subunits. Proc Natl Acad Sci USA 96:5262-5267. 